\title{
Le conflit tchétchène à l'épreuve de la reconnaissance
}

Questioning the Chechen Conflict through Recognition

Aude Merlin et Anne Le Huérou

\section{(2) OpenEdition \\ 12 Journals}

Édition électronique

URL : http://journals.openedition.org/conflits/18475

DOI : $10.4000 /$ conflits. 18475

ISSN : $1777-5345$

Éditeur :

CCLS - Centre d'études sur les conflits lilberté et sécurité, L'Harmattan

Édition imprimée

Date de publication : 26 décembre 2012

Pagination : 47-68

ISBN : 978-2-336-00248-4

ISSN : 1157-996X

Référence électronique

Aude Merlin et Anne Le Huérou, "Le conflit tchétchène à l'épreuve de la reconnaissance », Cultures \& Conflits [En ligne], 87 | Automne 2012, mis en ligne le 26 décembre 2013, consulté le 30 mars 2021.

URL : http://journals.openedition.org/conflits/18475; DOI : https://doi.org/10.4000/conflits. 18475 


\section{Le conflit tchétchène à l'épreuve de la reconnaissance}

\section{Aude MERLIN et Anne LE HUÉROU}

Anne Le Huérou est maître de conférences en civilisation russe à l'Université Paris Onest Nanterre la Défense, chercheure associée au CERCEC (CNRS/EHESS). Elle travaille en particulier sur les violences en Russie au sein du programme de recherche Comprendre les violences en Russie et sur l'impact des deux guerres de Tchétchénie sur la société russe. Elle a récemment publié "Massacres de civils en Tchétchénie » dans l'Encyclopédie en ligne des violences de masse (avec Amandine Regamey), juin 2012. http://www.massviolence.org/Massacres-de-civils-enTchetchenie

Aude Merlin est maître de conférences en science politique à l'ULB (Université libre de Bruxelles), membre du CEVIPOL. Auteur d'une thèse sur le Caucase du Nord, elle consacre une partie de ses travaux au conflit tchétchène, et aux enjeux de mobilisation au Caucase du Nord. Elle a récemment publié "Repenser le lien entre violences et États au Caucase ", Dynamiques Internationales, n6, Février 2012 (avec Silvia Serrano).

$V$

toräa tchetchenskä̈a, littéralement « la deuxième tchétchène » : c'est parfois par cette ellipse, cet évitement du mot guerre (voïna), comme dans le titre éponyme d'un livre d'Anna Politkovskaïa 1, qu'a pu être désignée la seconde guerre de Tchétchénie, lancée en septembre 1999, et dont il est impossible de dater la fin 2. Elle souligne l'évidence de la guerre pour les uns - les civils en premier lieu, les journalistes et défenseurs des droits de l'Homme, mais aussi les militaires russes et combattants tchétchènes sur le terrain -, qui contraste avec le hiatus entre le discours officiel qui refuse de qualifier comme tel le conflit, et l'expérience vécue par les protagonistes, combattants ou civils, tchétchènes ou russes.

1. Politkovskaia A., Vtoraia Tchetchenskaia, Moscou, Zakharov, 2002. Anna Politkovskaïa avait repris cette expression de ses nombreux entretiens avec des soldats russes.

2. Sur la difficulté de dater l'hypothétique fin de la deuxième guerre de Tchétchénie, voir Merlin A., «Tchétchénie : un après guerre sans paix », in Merlin A. et Serrano S. (eds.), Ordres et désordres au Cancase, Éditions de l’Université de Bruxelles, Bruxelles, 2010. 
Nous proposons dans cette contribution une réflexion sur la relation entre guerre et reconnaissance à partir du cas russo-tchétchène selon deux aspects : d'une part, les enjeux discursifs autour de la qualification du conflit et les effets produits par ces discours sur l'évolution même de la guerre; d'autre part, les enjeux symboliques, y compris de longue durée, qui peuvent permettre de comprendre une logique d'escalade débouchant, par deux fois depuis l'effondrement de l'Union soviétique, sur le recours à la violence armée et sur la conduite d'opérations militaires de grande ampleur.

Pour situer brièvement les principales étapes du conflit, on peut rappeler ceci : l'expression de revendications indépendantistes tchétchènes pendant la pérestroïka en URSS se traduit le $1^{\text {er }}$ novembre 1991 par une déclaration unilatérale d'indépendance du général Djokhar Doudaev, à la faveur de l'éclatement en cours de l'URSS. Le nouvel État russe n'accepte pas ce précédent : le pouvoir indépendantiste à Grozny défie constamment le pouvoir fédéral en instaurant un contrôle sur la République tchétchène qui échappe à Moscou. Après trois ans de bras de fer politique, le pouvoir russe finit par décider une intervention militaire pour « rétablir l'ordre constitutionnel » et « désarmer les bandes armées illégales » : une véritable guerre se déroule de décembre 1994 à août 1996, marquée par des bombardements massifs de Grozny et autres villes et villages, de nombreuses exactions de l'armée contre les civils ${ }^{3}$, l'usage de la torture et l'organisation d'un système de filtration ${ }^{4}$. Malgré des accords de cessez-le-feu en 1996 prévoyant une période de transition et des élections supervisées par l'Organisation pour la sécurité et la coopération en Europe (OSCE), la période qui suit est très chaotique : la Tchétchénie de l'après-première guerre (1996-1999), présidée par l'indépendantiste Aslan Maskhadov démocratiquement élu, est caractérisée par la faiblesse du pouvoir politique local, l'influence croissante de courants islamistes radicaux, la multiplication des prises d'otages et autres activités criminelles de groupes armés non démobilisés, et un isolement progressif de la région ${ }^{5}$.

La reprise de la guerre à l'automne 1999, cette fois qualifiée par le pouvoir russe de "lutte contre le terrorisme », coïncide avec l'arrivée au pouvoir de Vladimir Poutine. La phase de guerre ouverte et à grande échelle se poursuit pendant plusieurs mois, mobilisant plus de 100000 soldats et policiers des forces fédérales, aux prises avec quelques milliers de combattants tchétchènes ${ }^{6}$. Elle culmine avec la prise de Grozny en février 2000 et se commue

3. Memorial, By All Available Means: The Russian Federation Ministry of Internal Affairs Operation in the Village of Samashki: April 7-8, 1995 (rapport d'une mission d'observation), Moscou, 1996 ; Rossia-Tchetchnia, Tsep'oshibok i prestuplenii [Russie-Tchétchénie, un enchaînement d'erreurs et de crimes], Moscou, Zvenia, 1998.

4. Directive $\mathrm{n}^{\circ} 247$ du MVD (ministère de l'Intérieur) portant création des « points de filtration temporaires ", 12 décembre 1994 ; Memorial, Rossia-Tchetchnia, tsep’ ..., op. cit., p. 214.

5. Merlin A., «Après-guerre en Tchétchénie : les spoilers à l'assaut de l’État tchétchène en formation (1996-1999) ", in Duclos N. (ed.), L'adieu aux armes? Parcours d'anciens combattants, Paris, Karthala, 2010, pp. 325-357. 
peu à peu en guerre d'occupation, caractérisée par des opérations répétées de "nettoyage » (zatchistka) dont le prétexte est la recherche des combattants engagés dans des actions de guérilla. Rafles et enlèvements se multiplient, donnant lieu à un usage massif de la torture et des mauvais traitements de la part des forces fédérales. À partir de 2003-2004, on observe une transformation du conflit, la «pacification » étant progressivement confiée à des forces tchétchènes loyales à Moscou. Ramzan Kadyrov, nommé officiellement président en 2007 et soutenu par Moscou, construit un pouvoir sans partage, unifiant sous ses ordres l'ensemble des forces de l'ordre tchétchènes et enrôlant plusieurs milliers d'ex-combattants indépendantistes. Si en 2009 , la fin officielle de «l'opération antiterroriste » est proclamée, une guerre de basse intensité se poursuit néanmoins, mettant face à face les forces de l'ordre de la république de Tchétchénie et des groupes de combattants. Par ailleurs, la violence se diffuse dans toute la région ${ }^{7}$.

Pour tenter de définir ce conflit, il faut sans doute commencer par s'interroger sur la manière dont joue son inscription dans une temporalité particulière qui voit se succéder la décomposition de l'URSS et l'émergence des conflits de l'après-guerre froide. Ceux-ci sont souvent envisagés sous l'angle de ces «nouvelles guerres ${ }^{8}$ qui brouillent les frontières entre conflit interétatique et guerre civile, mêlent motivations territoriales, religieuses, politiques ou criminelles dans des affrontements armés que se livrent plus souvent des milices que des armées régulières et dont les principales cibles sont les civils. Le droit de la guerre lui-même s'en est trouvé fortement remis en cause, comme l'attestent les nombreux débats autour de la légitimité des interventions étrangères ${ }^{9}$, ainsi que l'émergence d'une justice pénale internationale.

Le conflit russo-tchétchène tel qu'il éclate après l'effondrement de l'URSS pourrait par plusieurs aspects relever de cette définition - conflit intra-étatique, dissymétrique, n'opposant pas deux armées régulières de deux États indépendants, et ayant pour victimes principales les civils ; importance crois-

6. Facon I., «La seconde guerre de Tchétchénie, les aspects politico-militaires », Annuaire français des Relations internationales, 2002 (http://www.afri-ct.org/IMG/pdf/facon2002.pdf, consulté le 22/07/2012.

7. Pour des références générales sur le conflit, on se reportera à Hughes J., Chechnya: From Nationalism to Jihad, Philadelphie, University of Pennsylvania Press, 2007 ; Evangelista M., The Chechen Wars. Will Russia go the Way of the Soviet Union?, Washington D.C., Brookings Institutions Press, 2003 ; Gall C., De Waal Th., Chechnya, Calamity in the Cancasus, New York et Londres, New York University Press, 1998 ; Lieven A., Chechnya, Tombstone of Russian Power, Yale University Press, 1998 ; Le Huérou A., Merlin A., Regamey A., Serrano S., Tchétchénie, une affaire intérieure? Russes et Tchétchènes dans l'étan de la guerre, Paris, Autrement, 2005.

8. Kaldor M., New \& Old Wars. Organized Violence in a Global Era, Stanford, Stanford University Press, 2007 [1999].

9. Hassner P., Marchal R. (eds.), Guerre et Société : État et violence après la guerre froide, Paris, Karthala, 2003 ; Hassner P., Andreani G., Justifier la guerre?, Paris, Presses de la FNSP, 2005 ; Nadeau Ch., Saada J., Guerre juste, guerre injuste, histoire, théories et critiques, Paris, PUF, 2009 ; Jeangène-Vilmer J.-B., La Guerre au nom de l'bumanité. Tuer ou laisser mourir, Paris, PUF, 2012. 
sante de l'islam, composante économique autour des revenus du pétrole, frontière peu étanche entre combattants et réseaux criminels. Il nous semble pourtant s'en éloigner de manière décisive ne serait-ce que pour une raison majeure : la place centrale de l'État russe, qu'il s'agisse du contrôle des forces agissant en son nom, de sa stratégie de légitimation sur la scène internationale ou de la manière dont le camp opposé se définit initialement par une revendication territoriale d'indépendance qui évoque une autre logique, celle des conflits de décolonisation. Guerre interne plutôt que guerre civile, la guerre de Tchétchénie illustrerait la complexité de l'analyse des guerres contemporaines en étant située au carrefour des « deux grands récits moraux du XXe siècle 10 », celui du monde de l'après-guerre froide et celui de l'expérience coloniale dans laquelle elle s'inscrirait à plus d'un titre, mais comme «à retardement » par rapport aux grandes vagues de décolonisation des empires ultramarins des années 1960. Elle vient appuyer l'argument avancé par Stathis Kalyvas pour refuser une distinction finalement peu opératoire entre les conflits de l'avant et de l'après-guerre froide ${ }^{11}$.

En nous appuyant notamment sur des travaux menés autour des théories de la reconnaissance appliquées au phénomène guerrier ${ }^{12}$, nous nous proposons d'explorer ici quelques pistes d'analyse qui fassent toute leur place aux enjeux symboliques et montrent comment les stratégies discursives et de labellisation produisent des effets structurants sur l'évolution du conflit et son issue, ouvrant aussi la réflexion sur ce qui caractérise le « post-conflit » dans le cas de la Tchétchénie.

Dans une première partie, nous mettons l'accent sur la manière dont la labellisation du conflit s'est constituée en un véritable enjeu en Russie et à l'extérieur, pour montrer ensuite comment la question de l'affirmation identitaire et des enjeux symboliques intervient dans le déroulement des différentes phases du conflit. La conclusion déplace le questionnement vers le recours au droit intervenant moins dans le cadre d'une justice transitionnelle « postconflit » que comme un levier majeur, voire le seul possible en termes de qualification et de reconnaissance des crimes commis pendant le conflit.

10. Maier Ch., "Consigning the Twentieth Century to History. Alternative narratives for the modern era”, American Historical Review, vol. 165, n³, 2000, pp. 807-831, cité par P. Hassner, Guerre et sociétés : États et violence après la guerre froide, op. cit., p. 6.

11. Kalyvas S. N., “New' and 'Old' Civil Wars: A Valid Distinction?”, World Politics, 54-1, 2011, pp. 99-118.

12. Lindemann T., "Peace Through Recognition: An Interactionist Interpretation of International Crises”, International Political Sociology, 5-1, 2011, pp. 568-586 ; Causes of War, The Struggle for Recognition, Colchester, ECPR Press Monographs, 2010 ; Penser la guerre. L'apport constructiviste, Paris, L'Harmattan, 2008 ; Honneth A., La Lutte pour la reconnaissance, Paris, Cerf, 2000 [1992] ; Klotz A., Lynch C., Bouyssou R., Smouts M.C., «Le constructivisme dans la théorie des relations internationales ", Critique internationale, 2, 1999, pp. 51-62 ; Kratochwil F., “On the notion of 'interest' in international relations”, International Organization, 36-1, 1982, pp. 1-30 ; "Norms and values: rethinking the domestic analogy", Ethics E International Affairs, 1-1, 1987, pp. 135-159. 


\section{Comment ne pas la nommer ? Production pléthorique de discours et significations d'un évitement}

"Opération antiterroriste », " combat pour l'indépendance ", « guerre sainte ", " génocide », " guerre coloniale » ou " guerre civile » : ces termes, parmi d'autres, ont été utilisés par l'une ou l'autre des parties au conflit de même que par différents observateurs extérieurs. Si la profusion des labels n'est en rien propre au conflit tchétchène, la manière dont il s'inscrit dans des schémas discursifs et interprétatifs au croisement des conflictualités intérieure et internationale peut permettre d'éclairer plusieurs de ses enjeux, qu'il s'agisse de sa perception ou des effets produits sur son déroulement. Dans la dégénérescence d'une crise politique née d'une situation inédite - la décomposition de l'URSS - en conflit armé, la construction du nouvel État russe dans un répertoire d'action voulu comme démocratique nous livre une clé d'interprétation centrale, que nous examinerons à partir des différents discours.

\section{La Tchétchénie, enjeu de basse intensité pour la " communauté internationale ». Producteurs de discours et effets de la (non) qualification}

Sur le plan du droit international, le conflit russo-tchétchène n’a quasiment jamais fait l'objet d'une reconnaissance en tant que conflit armé international. Sur le plan interne, qu'il s'agisse de décembre 1994 ou de septembre 1999, ni l'état de guerre ni même l'état d'urgence, encadré par la loi russe et nécessitant l'intervention du Parlement, n'ont été déclarés ${ }^{13}$. La seule prise à une analyse dans ce sens est fondée sur les accords de paix russo-tchétchènes de mai 1997 : ceux-ci stipulaient en effet que la Russie et la Tchétchénie établissaient leurs relations sur les principes du droit international ${ }^{14}$. Cette position est néanmoins restée très marginale dans la mesure, entre autres, où presque aucun État n'a reconnu la Tchétchénie-Itchkérie d'A. Maskhadov issue des élections de $1997^{15}$, pas plus que la première indépendance proclamée en 1991.

Au regard du droit international des conflits armés, le conflit est le plus souvent qualifié, principalement par les experts et les ONG internationales et non par les États ni par les organisations interétatiques, de conflit armé non international (CANI) ${ }^{16}$. Les analyses ne se prononcent pas sur le bien-fondé

13. Le seul moment où la question a été posée fut lorsque la fraction communiste de la Douma voulut enclencher, en 1995, une procédure d'impeachment à l'encontre du président Boris Eltsine, lui reprochant d'avoir déclenché des opérations militaires sans l'accord du Parlement.

14. DiPaola P. D., "A Noble Sacrifice? Jus ad Bellum and the International Community's Gamble in Chechnya", Indiana Journal of Global Legal Studies, 4-2, 1997, pp. 435-470.

15. Seul l'Afghanistan des talibans a reconnu la Tchétchénie indépendante, et ce en 2000 seulement. La Russie avait menacé de rompre ses relations diplomatiques avec tout État qui reconnaîtrait la Tchétchénie indépendante. $C f$. Kherad R., « De la nature juridique du conflit tchétchène ", Revue générale de droit international public, janvier 2000, p. 171. 
du projet d'indépendance mais sur l'asymétrie des forces en présence, la disproportion dans l'usage de la force de la part de l'État russe et les violations massives qu'il commet en tant qu'État membre de l'ONU, de l'OSCE et du Conseil de l'Europe, signataire des conventions internationales régissant le droit de la guerre et la protection des populations civiles ${ }^{17}$, quelles que soient par ailleurs les violations commises par la rébellion armée tchétchène ${ }^{18}$.

C'est donc en fonction de ces normes que les institutions internationales ont été appelées, sinon à se prononcer sur la nature du conflit, au moins à réagir en utilisant en partie les ressources du jus ad bellum pour en qualifier les violations. Elles sont en même temps parties prenantes d'un jeu politicodiplomatique complexe consistant à établir ou maintenir des relations avec le nouvel État russe dans le contexte de l'après-guerre froide.

Jamais abordée de front par les Nations Unies comme un conflit non international susceptible de relever du «droit d'ingérence » ou de « l'intervention humanitaire » 19 , la gestion du conflit russo-tchétchène a été de facto déléguée aux institutions en charge des droits de l'Homme. Des résolutions de la Commission des droits de l'Homme faisant référence à l'« emploi disproportionné et sans discernement de la force militaire par la Russie » sont votées en avril 2000 et 200120 mais elles ne demandent pas la création d'une commission d'enquête. L'ONU est ainsi devenue, au fil des années, une arène d'expression publique et de plaidoyer pour les représentants indépendantistes tchétchènes en Europe et surtout pour les ONG russes et internationales qui ont déployé une expertise reconnue ${ }^{21}$, mais sans prise sur la capacité d'action de l'institution et sans plus de résultat tangible.

16. Ibid.; FIDH, "Tchétchénie. Crimes contre l'humanité. Quand leurs auteurs seront-ils jugés ? ", février 2000, http://www.fidh.org/IMG/pdf/crimtche.pdf ; http://www.fidh.org/IMG/pdf/crimtche.pdf ; Human Rights Watch, "'Welcome to Hell': Arbitrary Detention, Torture, and Extortion in Chechnya, 1er octobre 2000, http://www.unhcr.org/refworld/docid/3ae6a8750.html (consulté le 15 août 2012) ; Míšová M., The Legal Character of the Conflict in Chechnya, Prague Watchdog, 2001, http://www.watchdog.cz/index.php?show=000000-000004-000003-000019\&lang=1\# ; Dmitrievski S., Gvareli B., Chelysheva O., Mezhdunarodny tribunal dlia Chechni (Un tribunal international pour la Tchétchénie), t.1 et 2, Nijni-Novgorod, 2009, http://www.tribunalchr.info/ (consulté le 30/06/2011).

17. Hansen G., Seely R., War and Humanitarian Action in Chechnya, Occasional paper $n^{\circ} 26$, Providence (Rhode Island), Thomas J. Watson Institute for International Studies, 1996, http://www.watsoninstitute.org/pub/OP26.pdf (consulté le 24/07/2012).

18. Certains commentaires politiques, s'éloignant des définitions juridiques, ont pu contenir un jugement plus politique : c'est par exemple le cas du ministre français des Affaires étrangères Hubert Védrine, qui fait référence à mots couverts à l'expérience passée de la France pour donner plus de poids à ses propos lorsqu'il déclare en février 2000 qu'il s'agit d'un " problème colonial » qui ne peut être résolu par la force : http://tempsreel.nouvelobs.com/monde/20000202.OBS1743/hubert-vedrine-plaide-pourune-solution-politique-du-conflit-tchetchene.html (consulté le 20 juillet 2012).

19. On ne peut, dans le cadre de cet article, aborder les problèmes posés par ces notions. Mieux définie par l'ONU, celle de "responsabilité de protéger » instituée en 2005 n'était pas en vigueur lors des phases actives du conflit.

20. Commission des droits de l'homme des Nations Unies, résolution E/CN.4/RES/2000/58 du 25 avril 2000 et E/CN.4/RES/2001/24 du 20 avril 2001. 
Présente sur le terrain pendant le premier conflit et dans l'après-guerre jusqu'en décembre 1998, l'OSCE joue à l'époque une partie de sa crédibilité institutionnelle et politique 22 dans cette mission unique en son genre (c'est le seul cas où l'organisation est intervenue en tant que médiatrice dans un conflit interne). Attentive au soutien de l'État russe nécessaire à sa présence sur le territoire, elle avance une position prudente tout en appelant à une solution politique et en " condamnant les violations flagrantes du droit international et des principes de l'OSCE découlant de la campagne militaire de la Fédération de Russie en Tchétchénie 23 ». Alors que reprend la guerre à l'automne 1999 24, l'organisation, qui espère pouvoir rouvrir une mission sur place, condamne l'emploi disproportionné de la force par l'armée russe tout en reconnaissant l'intégrité territoriale de la Fédération de Russie et la nécessité de lutter contre le terrorisme. Mais la partie russe oppose une fin de non-recevoir à toute proposition de médiation.

Les hésitations sur la qualification des faits se répercutent sur la capacité des États à agir, collectivement comme de manière bilatérale. La seule exception notable a lieu au moment de l'ultimatum lancé par l'armée russe à tous les habitants de Grozny le 6 décembre 199925 : la fermeté unanime de l'OSCE mais aussi de l'UE pousse les autorités russes à renoncer à l'ultimatum ${ }^{26}$. Les mois qui suivent verront la plupart des pays européens adopter des positions beaucoup plus retenues avant que les évènements du 11 septembre 2001 ne viennent aplanir ces divergences 27 .

21. Voir par exemple tous les rapports et notes rédigés à l'occasion des sessions de la Commission puis du Conseil des droits de l'Homme, les rencontres avec les experts des mécanismes spéciaux ou encore le rapport alternatif élaboré par une coalition d'ONG russe lors de l'examen périodique de la Russie devant le Comité des Nations unies contre la torture en novembre 2006 (http://www2.ohchr.org/english/bodies/cat/docs/ngos/joint-russian-report-new.pdf, consulté le 22/03/2012).

22. Lucas M. R., "A marriage of convenience. The OSCE and Russia in Nagorny-Karabakh and Chechnya", Helsinki Monitor, 2, 1996, p. 15, in Monod L., "Le rôle de l'OSCE en Tchétchénie », http://www.stoessel.ch/hei/PS/OSCE_en_Tchetchenie.htm (consulté le 23/07/12).

23. Déclaration d'Ottawa de l'Assemblée parlementaire de l'OSCE, juillet 1995, http://www.osce.org/fr/pa/38134 (consulté le 23 juillet 2012).

24. Les bombardements de l'OTAN sur la Serbie quelques mois auparavant ont ouvert une crise sérieuse entre la Russie et les Occidentaux.

25. Cet ultimatum enjoint à toute la population de quitter la ville sous peine d'être bombardée : Roth H., "Ceux qui resteront à Grozny seront des terroristes », Tribune de Genève, 7 décembre 1999.

26. Le 10 décembre, le sommet des chefs d'États de l’Union européenne à Helsinki menaçait la Russie de sanctions, en particulier la suspension de certains financements : Conseil européen d'Helsinki, 10 et 11 décembre 1999, déclaration finale, annexe II http://www.consilium.europa.eu/ueDocs/cms_Data/docs/pressData/fr/ec/00300-r1.f9.htm ; déclaration du président du G8 demandant un « cessez-le-feu immédiat et permanent dans toute la Tchétchénie ", Berlin, 17 décembre 1999 http://www.g8.utoronto.ca/foreign/fm991216chair.htm ; OSCE, "OSCE Parliamentary Assembly President concerned about Chechnya situation ", 10/12/1999, http://www.osce.org/pa/52277 (consulté le 19/07/2012) ; OSCE, «Statement by OSCE Chairman-in-Office on the conflict in Chechnya ", 29/12/1999, http://www.osce.org/cio/52275, (consulté le 19/07/2012). 
Au total, malgré un engagement fort en 1994-1996, l'OSCE n'est donc pas parvenue à peser sur la situation en Tchétchénie, conflit qui a durablement affaibli sa crédibilité 28 . Si cette institution, dont la vocation première est le maintien de la sécurité et la résolution des conflits, ne parvient pas à s’imposer à partir de 1999, c'est plus pour des raisons politiques que pour un défaut de qualification juridique du conflit, ce qui témoigne de l'évolution des rapports de force entre la Russie et ses partenaires européens.

Comme dans le cas de l'OSCE, le conflit tchétchène tient une place centrale dans l'histoire des relations entre le Conseil de l'Europe et la Russie ${ }^{29}$, mais de manière plus durable et systématique. Différée en raison de la guerre, l'entrée de la Tchétchénie au Conseil de l'Europe est finalement actée au printemps 1996 malgré la poursuite des hostilités ${ }^{30}$. Lorsque le conflit reprend à l'automne 1999, l'Assemblée parlementaire du Conseil de l'Europe (APCE) condamne très rapidement la conduite des opérations par la Russie ${ }^{31}$, sans se prononcer toutefois sur la nature du conflit. Rapports et résolutions de l'APCE se multiplient pour dénoncer les violations massives des droits de l'Homme, qualifiées en 2003 de crimes de guerre et de crimes contre l'humanité ${ }^{32}$. Cependant, les appels répétés des ONG internationales et de l'APCE elle-même pour une implication du Comité des ministres vis-à-vis de l'État russe restent sans lendemain. La seule mesure de sanction a été la suspension pendant six mois du droit de vote de la délégation russe à l'Assemblée, déci-

27. Sur les répercussions du 11 septembre, voir Le Huérou A., Regamey A., « La guerre russe en Tchétchénie : discours antiterroriste et légitimation de la violence ", Critique internationale, 41, 2008, pp. 99-118.

28. Ghebali V. H., "La crise tchétchène devant l’OSCE », Défense nationale, 51-5, 1995, pp. 93102 ; Ghebali V. H., "Growing Pains at the OSCE: The Rise and Fall of Russia's PanEuropean Expectations”, Cambridge Review of International Affairs, 18-3, 2005, pp. 375388.

29. Pour une analyse détaillée, voir Francis C., «La guerre en Tchétchénie : quelle efficacité du Conseil de l'Europe face à des violations massives des droits de l'Homme ?", Revue trimestrielle des droits de l'Homme, 57, 2004, pp. 77-99 et "Selective Affinities': The Reactions of the Council of Europe and the European Union to the Second Armed Conflict in Chechnya (1999-2006)", Europe-Asia Studies, 60-2, 2008, pp. 317-338.

30. Massias J. P., "Russia and the Council of Europe: Ten Years Wasted?", Russie.Nei Visions (IFRI) n॰15, janvier 2007, www.ifri.org/.../ifri_CE_massias_ang_jan2007.pdf (consulté le 24 juillet 2012).

31. Elle « condamne, comme totalement inacceptable, la conduite actuelle d'opérations militaires en Tchétchénie, avec ses conséquences tragiques pour de nombreux civils de cette république ». Elle estime que «ce recours inconsidéré et disproportionné à la force viole de manière très grave les droits fondamentaux de civils tchétchènes non belligérants et innocents, notamment leur droit à la vie, à la liberté et à la sécurité »(APCE, 27/01/2000). Voir Le Huérou A., Regamey A., " Massacres de civils en Tchétchénie », Encyclopédie en ligne des violences de masse [en ligne], publié le 13 juillet 2012, http://www.massviolence.org/Massacres-de-civils-en-Tchetchenie (consulté le 15 août 2012).

32. Voir notamment : résolution 1323 (2003) «La situation des droits de l'homme en République tchétchène ", http://assembly.coe.int/Documents/AdoptedText/ta03/FRES1323.htm ; et jusqu'à la résolution 1738 adoptée par l'Assemblée le 25 juin 2010 suite au rapport de Dick Marty sur l'impunité des crimes de guerre, Doc. 12276 du 4 juin 2010, http://assembly.coe.int/Mainf.asp?link=/Documents/AdoptedText/ta10/ FRES1738.htm (consultés le 15 août 2012). 
dée lors de la session d'avril 2000 par les parlementaires. Par la suite, en choisissant d'endosser une position d'observateur du conflit avec la création d'une commission ad hoc en Tchétchénie ${ }^{33}$, l'organisation s'est retrouvée à cautionner de facto la logique de guerre ${ }^{34}$ tout en remettant à son bras judiciaire, la Cour européenne des droits de l'homme (CEDH), le soin de juger des violations commises (voir infra).

Ce refus (ou cette impossibilité) des grandes organisations internationales à estimer que ce conflit mérite une attention et des actions plus soutenues vient souligner la «faible intensité » de l'enjeu tchétchène sur la scène internationale. Au fil des années, la guerre en Tchétchénie n’est plus guère évoquée que dans le cadre de la lutte contre le terrorisme international : le discours de l'antiterrorisme est en effet l'énonciation centrale de la seconde guerre, et voit se rapprocher positions russe et occidentale après le 11 septembre. L'effet d'aubaine est double : pour la Russie qui mène une guerre populaire dans l'opinion publique russe, assortie d'un nouveau positionnement international ; pour les responsables occidentaux qui peuvent placer la Tchétchénie au rang des dommages collatéraux de la guerre contre le terrorisme ${ }^{35}$.

\section{Quête et besoin de reconnaissance du nouvel État russe : usages interne et externe}

Derrière cette présentation somme toute « réaliste » des enjeux de qualification, apparaît une autre dimension, beaucoup plus symbolique, qui joue particulièrement pour le premier conflit : celle d'un désir mutuel de reconnaissance entre la Russie post-soviétique et le monde occidental dans le contexte de l'après-guerre froide. Au début des années 1990, la Russie non seulement poursuit une politique étrangère résolument tournée vers l'Occident mais

33. Commission créée suite à la suspension du droit de vote d'avril 2000 en vue de chercher un apaisement et dans l'espoir de permettre à l'organisation de peser sur la conduite de la guerre. Elle avait la charge de formuler des recommandations de bonne conduite aux forces armées russes en relation avec le représentant spécial russe pour les droits de l'Homme en Tchétchénie nommé par Poutine, Vladimir Kalamanov. Cette commission s’installe dans le nord de la république et bien que constatant régulièrement son impuissance, reste en place jusqu'en 2004.

34. Voir : Tchétchénie, Dix clés pour comprendre, Paris, La Découverte, 2003 (rééd. 2005), chap. 10 ; Lemaitre R., "Can the European Court of Human Rights Provide Justice for Victims of Russian Human Rights Abuses in Chechnya?”, in Malfliet K., Parmentier S. (eds.), Russia and the Council of Europe: 10 years after, New York, Palgrave Macmillan, pp.165-186; Merlin A., "Gambling, Misunderstanding or Compromising? The Council of Europe and the War in Chechnya”, in op. cit., pp. 137-165.

35. La Russie cherche à diversifier ses intérêts et ses alliances, pouvant à la fois jouer de son inclusion dans la coalition "War on terror » et s'engager au nom de la lutte contre le terrorisme dans des alliances avec les régimes autoritaires d'Asie centrale ou de Chine autour de la convention de Shangaï. Voir Le Huérou A., Regamey A., "La guerre russe en Tchétchénie : discours anti-terroriste et légitimation de la violence », op. cit. ; Le Huérou A., "Fédération de Russie : l'antiterrorisme comme instrument de pouvoir ", in Bigo D., Bonelli L., Deltombe T. (eds.), Au nom du 11 septembre... Les démocraties à l'épreuve de l'antiterrorisme, Paris, La Découverte, 2008, pp. 260-273. 
s'affirme comme un État démocratique. Cette énonciation est globalement reprise par les Occidentaux, qui en dépit de la guerre en cours, considèrent le conflit tchétchène comme un accident de parcours regrettable 36.

Au-delà de l'intérêt stratégique qui conduit les autorités russes à présenter ainsi l'intervention militaire, il ne faut pas négliger, du point de vue de la reconnaissance, une forme de quête en miroir : la demande de reconnaissance de l'indépendance tchétchène, unilatéralement proclamée en novembre 1991, ressort d'une affirmation identitaire qui cherche à faire reconnaître le caractère colonial de l'incorporation forcée de la Tchétchénie à l'Empire tsariste puis à la Russie soviétique ; elle puise sa légitimité dans l'histoire ( $c f$. infra) mais aussi dans le passé plus récent de la fin de l'URSS, lorsque les mouvements nationaux et les revendications de souveraineté rencontrent un écho favorable chez B. Eltsine, celui-là même qui va décider de la guerre en décembre 1994. On touche là à un malentendu de taille : aboutissement logique des encouragements à la souveraineté prononcés par B. Eltsine lorsqu'il n'était pas encore à la tête d'un État cherchant à faire reconnaître ses frontières internationales, l'indépendance est aussi perçue, côté tchétchène, comme la « récompense » du soutien apporté par D. Doudaev à ce dernier lors du putsch de 1991 ; à l'inverse, pour les dirigeants russes, elle constitue un camouflet, une trahison à l'encontre du camp censé incarner la démocratie.

Le malentendu repose aussi sur le fait que cette demande de reconnaissance est adressée à un État lui-même en quête de légitimité sur le plan intérieur comme sur la scène internationale. La peur d'un « effet domino » de l'indépendance tchétchène sur d'autres régions, d'une Russie qui éclaterait comme a éclaté l'URSS, n'est donc pas qu'un effet de discours mais constitue aussi un ensemble de croyances fortes pour les élites politiques russes. S'il reste beaucoup à écrire sur la période allant de la déclaration d'indépendance tchétchène en 1991 au déclenchement des opérations militaires en décembre 1994, les sources et documents existants montrent comment, sans négliger des éléments relevant du paradigme réaliste - conflits ou convergences d'intérêts entre élites indépendantistes tchétchènes et dirigeants russes ${ }^{37}$-, la dynamique des relations met en jeu des éléments tout autant symboliques que stratégiques ${ }^{38}$.

36. La même situation s'était produite en octobre 1993 au moment du bombardement du Parlement par B. Eltsine, justifié par la nécessité d'empêcher le blocage des réformes par les députés.

37. Pour le partage de circuits commerciaux, trafics, revente d'armes de stocks de l'armée soviétique, sans oublier l'acheminement du pétrole d'Azerbaïdjan.

38. Malashenko A., Trenin D., Vremja Yuga. Chechnya v Rossii i Rossija v Chechne (Le temps du Sud. La Tchétchénie en Russie et la Russie en Tchétchénie), Moscou, Moskovskij Center Carnegie, 2002 ; Lieven A., Chechnya, Tombstone of Russian Power, op. cit. 
La volonté de s'inscrire dans la dynamique d'un État démocratique en construction va aussi motiver les arguments des opposants à la guerre en Russie. Plus nombreux pendant le premier conflit, souvent proches du pouvoir jusqu'au déclenchement de la guerre, journalistes, intellectuels, personnalités politiques et militants des droits de l'Homme utilisent plutôt le registre propre à la «guerre civile » pour condamner l'emploi de la force armée et les violences massives contre les civils en invoquant la qualité de citoyens russes des Tchétchènes plus que celle de peuple colonisé en lutte pour son indépendance ${ }^{39}$. L'opinion russe juge elle aussi le conflit de 1994-1996 comme illégitime, même si cette condamnation traduit un autre enjeu symbolique, celui de la dégradation de l'image de l'État, incapable de mener la guerre éclair promise contre les «bandits " ${ }^{40}$. Ces ressentis sont présents jusque dans les rangs de l'armée, dont certains officiers n'hésitent pas à laisser passer les mères de soldats russes venues rechercher leurs fils conscrits sur le champ de bataille.

Lorsqu'en août 2008, un conflit a opposé deux États souverains, la Russie et la Géorgie, le mot "guerre » a été utilisé par les deux parties. C’est la première fois que la Russie est officiellement en guerre depuis 1945 : le culte mémoriel de la Grande guerre patriotique (1941-1945) avait quasiment sacralisé ce terme ${ }^{41}$. Or cette désignation officielle s'accompagne en Géorgie d'un modus operandi bien différent du cas tchétchène. Si des violations des droits de l'Homme ont été répertoriées ${ }^{42}$, les observateurs sur place ont pu constater de la part des militaires et policiers russes un comportement globalement bien plus attentif au droit des conflits armés et de la population civile, à l'opposé de tout ce qui a été observé et décrit en Tchétchénie ${ }^{43}$. Conscience d'être

39. Seules quelques mouvances anarchistes et antimilitaristes ou quelques personnalités parlent de guerre coloniale et reconnaissent le droit à l'indépendance de la Tchétchénie.

40. Voir Le Huérou A. «La société civile en Russie face à la guerre en Tchétchénie » in Merlin A. (ed.), Où va la Russie ?, Bruxelles, EUB, 2007, pp. 189-200 ; "L'opinion russe face à la guerre en Tchétchénie », in Hassner P., Marchal R. (eds.), Guerre et société : État et violence après la guerre froide, Paris, Karthala, 2003, pp. 165-191.

41. Voir le numéro intitulé "Contemporary Uses of the Second World War in Russia and the Former Soviet Republics” de la revue en ligne Power institutions in Post-soviet societies, 12, 2011, et notamment Voisin V., “Introduction” (http://pipss.revues.org/3896, consulté le 27/09/2012); Tumarkin N., The Living and the Dead. The Rise and Fall of the Cult of World War II in Russia, New York, Basic Books, 1994 ; Sapper M., " Povsednevnost' voinstvennosti v Rossii : nasledie militarizovannoro socializma " (Le bellicisme au quotidien en Russie. L'béritage du socialisme militarisé), The Journal of Power Institutions in Post-Soviet Societies, 3, 2005. L'intervention en Afghanistan, longue de dix ans, avait également donné lieu à des efforts rhétoriques de la part du pouvoir soviétique pour contourner le terme de guerre par des périphrases comme celle du devoir internationaliste.

42. «Up in Flames. Humanitarian Law Violations and Civilian Victims in the Conflict over South Ossetia ", Rapport de Human Rights Watch, 2009, http://www.hrw.org/sites/default/files/reports/georgia0109web.pdf (consulté le 27/09/2012).

43. Outre tous les rapports des organisations russes et internationales de défense des droits de l'Homme, voir Le Huérou A., Regamey A., " Massacres de civils en Tchétchénie », Encyclopédie en ligne des violences de masse, art. cit. 
engagé dans un conflit interétatique et, par conséquent, d'être plus exposé ? Ordres explicites de retenue ? Brièveté du conflit ? Les explications peuvent varier mais le contraste est tangible, qui fait d'autant plus ressortir le niveau de violence du conflit tchétchène et permet de poser la question du lien entre la nature d'un conflit et le type de violence qui s'y déroule ${ }^{44}$.

Une conséquence directe de la non-reconnaissance de la guerre par l'État russe est la manière dont sont traités ceux qui la font, à commencer par le décompte des morts parmi les soldats. À ce jour, il n'existe pas de données officielles sur le nombre de soldats de l'armée russe morts au cours des guerres de Tchétchénie. Les dispositions en faveur des vétérans, ou plutôt leur quasiabsence, sont éclairantes : elles ne prévoient quasiment rien pour les vétérans russes de Tchétchénie, qui jusqu'en 2002 ont reçu des documents de vétérans de la Grande guerre patriotique. À partir de cette date, ils sont assimilés aux « vétérans d'opérations menées hors des frontières de la Russie 45 » pour pouvoir recevoir quelques aides financières, et très rarement se voir proposer une réhabilitation ${ }^{46}$. La peur d'un "syndrome tchétchène ", qui se traduit de facto par des comportements violents et des passages à l'acte de la part des soldats et policiers ayant servi en Tchétchénie, est largement répandue ${ }^{47}$ mais sans que cela se traduise par une politique des pouvoirs publics en direction des vétérans. La psychologue clinicienne Françoise Sironi, qui a travaillé avec de nombreux vétérans, insiste dans sa description des traumatismes psychiques sur la responsabilité des institutions dans la prise en charge de la transition vers la vie civile des participants aux conflits armés ${ }^{48}$. Ce constat général est étayé par des recherches en cours ${ }^{49}$ ainsi que par le journaliste et écrivain Arkadi Babtchenko, lui-même vétéran des deux guerres de Tchétchénie ${ }^{50}$.

44. Kalyvas S. N., The Logic of Violence in Civil War, Cambridge, Cambridge University Press, 2006.

45. Bien souvent ces vétérans eux-mêmes parlent de « guerres locales ». Voir le site www.artofwar ou l'ouvrage de Ya. A. Gordin et al., My byli na etih vojnah. Svidetel'stva uchastnikov sobytij 1989-2000 godov [Nous avons été dans ces guerres. Témoignages de participants aux événements de 1989 à 2000], Saint-Pétersbourg, Zvezda, 2003.

46. Les Afgantsy, vétérans de la guerre d'Afghanistan, ont quant à eux obtenu de l'État des privilèges commerciaux à la fin la période soviétique qui leur ont souvent permis une adaptation plus facile aux transformations économiques, mais n'ont pas pour autant constitué une reconnaissance sociale de leur statut. Oushakine S., The Patriotism of Despair: Nation, War, and Loss in Russia, Ithaca \& London: Cornell University Press, 2009.

47. Le Huérou A., Sieca-Kozlowski E., « Les vétérans russes de la guerre de Tchétchénie, acteurs et vecteurs d'une transposition de la violence de guerre en "terrain propice" »? , in Duclos N. (ed.), L'Adien aux armes? Parcours d'anciens combattants, Paris, Karthala, 2010, pp. 41-81; Demos, Militsiia mejdou Rossieï i Tchetchneï. Veterany konflikta v rossiiskom obchtchestve (La police, entre Russie et Tchétchénie. Les vétérans du conflit dans la société russe), Moscou, Demos, 2008.

48. Voir notamment Sironi F., Psychopathologie des violences collectives. Essai de Psychologie géopolitique clinique, Paris, Odile Jacob, 2007.

49. Sieca-Kozlowski E., "L’État russe post-soviétique face à la souffrance psychique de guerre. Conception et héritage ", Revue d'Etudes comparatives Est-Onest, 45-4, à paraître en décembre 2012.

50. Arkadi Babtchenko anime notamment un site de littérature de guerre écrite par des vétérans de différents conflits, http://artofwar.ru. En français, Babtchenko A., La couleur de la guerre, Paris, Gallimard, 2009. 
Les registres mobilisés par les combattants tchétchènes sont-ils en phase avec cette évolution ? Le terme de guerre n'est donc non seulement pas évité par les porte-parole du projet indépendantiste tchétchène, mais il est associé à des formulations comme « combat pour l'Itchkérie indépendante » ou « libération de la Tchétchénie » qui traduisent une revendication politique et territoriale. C'est dans ce contexte qu'est mobilisé le terme politico-religieux de gazavat ${ }^{51}$, préféré à celui de jihad, même si des groupes islamistes aux objectifs autres que l'indépendance politique sont déjà présents durant le premier conflit. Durant le second, le discours dominant parmi les combattants glisse au fur et à mesure des années 2000 , et surtout après l'assassinat du président A. Maskhadov en 2005, vers celui du jihad, qui sous-tend une conception déterritorialisée du combat et s'exprime dans la volonté d'établir un État islamique dans l'ensemble du Nord-Caucase.

Au fur et à mesure du conflit apparaît une dissociation croissante des registres discursifs de part et d'autre, certains discours s'éloignant de l'enjeu premier, tandis que la logique d'expansion de la violence armée aux autres républiques du Nord-Caucase, pour des raisons qui ne se limitent pas à la revendication territoriale, brouille un peu plus les repères. Derrière ce sentiment d'une perte de sens et d'une fuite en avant des discours comme des actions menées, on peut aller puiser dans la longue durée des relations russotchétchènes ainsi que dans l'analyse de la situation ayant immédiatement précédé le déclenchement de la guerre pour comprendre les enjeux symboliques et politiques de reconnaissance susceptibles d'éclairer toutes les dimensions de ce conflit.

\section{Un conflit de reconnaissance ? Constructions identitaire et discursive tchétchènes}

«Pour comprendre les guerres, il faut certes déceler les logiques de l'bomo economicus ou de l'homo politicus, mais aussi - et peut-être surtout - celles de $l^{\prime}$ 'homo symbolicus ${ }^{52}$ ». Au-delà et en deçà du fait de nommer la guerre et donc de la reconnaître comme telle, une autre dimension est à prendre en compte au niveau symbolique, qui participe du hiatus entre l'image revendiquée et l'image renvoyée de la question tchétchène. Il s'agit des multiples niveaux où peut être décelé un défaut de reconnaissance : la reconnaissance de l'Autre en tant qu'ennemi légitime, porteur d'un projet légitime et interlocuteur potentiel pour d'éventuelles négociations. Les travaux d'Axel Honneth sur les effets du déni de reconnaissance et sur la lutte pour la reconnaissance ont apporté une dimension nouvelle à cette question, insistant davantage sur la place de la reconnaissance dans la construction identitaire et, en creux, pointant le déni de reconnaissance comme un élément important du recours éventuel à la vio-

51. Gazavat est le nom de la guerre sainte menée au XIX siècle contre l'Armée tsariste par les résistants tchétchènes et daghestanais conduits par l'imam Chamil, leader spirituel soufi.

52. Lindemann T., La Guerre, Paris, Armand Colin, 2010, p. 50. 
lence armée. Ainsi la dimension identitaire et de dignité occupe-t-elle une place non négligeable - combinée ou non avec les dimensions stratégiques et géopolitiques comme causes ou facteurs déclenchants des guerres - et c'est là qu'intervient la reconnaissance réciproque, comme l'écrit Honneth au sujet de la constitution d'un «sujet libre et digne 53 »: «Quelles que soient mes responsabilités et mon niveau de compétences, le développement de mon "je” présuppose des formes de reconnaissance réciproque dont je ressens le manque à travers l'expérience du mépris ${ }^{54}$ ».

Or, en amont des questions de labellisation analysées précédemment, cette dimension de la reconnaissance symbolique fait écho à une question centrale dans la façon dont sont perçues la revendication d'indépendance, puis la guerre, par divers segments de la société tchétchène. En dépit de divisions importantes qui travaillent la société tchétchène à différentes étapes de ses relations avec la Russie ${ }^{55}$, la récurrence des confrontations entre l'empire et ses marges nord-caucasiennes, et en particulier tchétchènes, a largement structuré l'imaginaire collectif tchétchène. La dissymétrie, déjà considérable sur les plans démographique et territorial ${ }^{56}$, est surtout déterminée par le prisme colonial renvoyant à l'histoire de la guerre du Caucase de 1818-1864 qui décima la population, coûtant la vie, notamment, à des dizaines de milliers de Tchétchènes ${ }^{57}$. Le fait que le territoire tchétchène ait été conquis et intégré dans l'espace politique russe accroît le défaut de reconnaissance et rend cette dissymétrie encore plus saillante que dans des conflits interétatiques ${ }^{58}$.

53. Comme l'écrit Axel Honneth, «La reconnaissance marque cet accès à soi qui passe par l'autre par lequel je m'éprouve sujet libre et digne ", in Honneth A., La Lutte pour la reconnaissance, Paris, Edition du Cerf, 2000.

54. Ibid.

55. Il y a eu dans l'histoire des relations russo-tchétchènes des séquences d'apaisement, et on trouve des figures comme celle de Beïboulat Taïmiev qui alterna entre phases de combat contre l'armée tsariste et phases de ralliement à cette dernière. Face à la déclaration d'indépendance en 1991, et durant les trois années qui précèdent la première guerre, la société tchétchène est très divisée, avec une opposition anti-doudaevienne qui se constitue. On retrouve de très forts clivages intra tchétchènes dans le sillage de la seconde guerre, avec la «tchétchénisation » du conflit et le transfert de prérogatives de violence à des forces tchétchènes dites pro-russes, inféodées à Ramzan Kadyrov.

56. Le territoire tchétchène actuel s'élève à $16000 \mathrm{~km}^{2}$, sur les 17 millions de $\mathrm{km}^{2}$ que représente le territoire russe. Ce rapport dissymétrique est très sensible également dans la dimension militaire et stratégique, les dizaines de milliers de fédéraux en armes présents à taux constant durant les deux guerres étant entre 10 et 20 fois plus nombre que les hommes tchétchènes en armes à taux constant. Pour les dimensions stratégiques de la première guerre, voir Knezys S., Sedlickas R., The War in Chechnya, College Station, A\&M University Press, 1999. La question démographique, en particulier au niveau des perceptions est peut-être plus ambivalente aujourd'hui, dans la mesure où les taux de fécondité nord-caucasiens revêtent une importance considérable en regard de la crise démographique que connaît la Russie. Néanmoins, le ratio que représentent les Tchétchènes à l'échelle de la population de toute la Fédération reste inférieur à $1 \%$.

57. L'ethnographe russe Adolphe Bergé conclut à la destruction de la moitié de la population tchétchène durant la guerre du Caucase. Voir Vatchagaev, op. cit., pp. 57-58.

58. Par exemple, l'ouvrage de T. Lindemann sur la reconnaissance dans la guerre se concentre essentiellement sur les conflits interétatiques. 
Par conséquent, on observe deux logiques qui s'emboîtent, dans la narration des entrepreneurs politiques tchétchènes indépendantistes : d'une part, le projet de voir la dimension coloniale reconnue; d'autre part, sur la base de cette reconnaissance, le projet de voir reconnue la légitimité d'une aspiration à la libération nationale, articulée ou non autour d'un réel projet indépendantiste, la fragilité de la grammaire politique tchétchène étant une donnée de l'équation. Mettant en jeu la reconnaissance, ces deux logiques révèlent un troisième enjeu : la reconnaissance de l'adversaire en tant que tel.

\section{L'bistoire comme enjeu de reconnaissance}

Face à la diffusion de stigmates assignés par les autorités russes ( $c f$. infra) et relayés par une grande partie des médias en Russie, l'accent est mis par certains porte-parole indépendantistes tchétchènes sur la réinscription du conflit et de la revendication d'indépendance dans une histoire du face-à-face avec la Russie. C'est ainsi que le terme de gazavat est mobilisé dès la première guerre de 1994-1996 59, en réaction au qualificatif de «bandit » 60 attribué aux combattants tchétchènes dans la rhétorique officielle russe sur l'" opération de désarmement des bandes illégalement formées ». En réinscrivant la confrontation en cours dans une histoire de combat spirituel et d'aspiration à la liberté 61 , il s'agit d'enrayer une violence symbolique telle que définie par Philippe Braud, au sens où « le dommage causé opère au niveau identitaire, c'est-à-dire affecte, de manière dépréciative, des représentations de soi 62 ». Dans le discours officiel russe, le stigmate de «bandits », largement mobilisé pendant la première guerre de 1994-1996, est relayé, dès le début de la seconde, par celui de «terroristes » 63 (voir supra) et le terme de « wahhabite », souvent utilisé mal à propos, est repris en russe pour désigner une partie des combattants, afin de mettre l'accent sur un caractère exogène, importé de la rébellion ${ }^{64}$. La manière de nommer les protagonistes est un nouveau dissensus qui s'ajoute à celui sur la qualification des événements.

59. Observations personnelles, Grozny, avril 1995. Voir aussi Moshe Gammer, op. cit.

60. Voir Russell J., “Terrorists, Bandits, Spooks and Thieves: Russian demonisation of the Chechens prior to and since 9/11", Third World Quarterly, 26-1, 2005, pp. 101-116.

61. On peut penser aux interventions publiques en Europe de représentants du gouvernement Maskhadov : Ilyas Akhmadov, ministre des Affaires étrangères ; Oumar Khanbiev, ministre de la Santé puis représentant spécial ; Akhmed Zakaev, ministre de la Culture, durant la première moitié des années 2000.

62. Braud P., Violences politiques, Paris, Seuil, 2004, p. 161.

63. La figure de l'abrek, combattant nord-caucasien pendant la guerre du Caucase au XIX ${ }^{\mathrm{e}}$ siècle, qui pour échapper à l'Armée tsariste continuait à vivre dans les montagnes en se cachant et en recourant à des larcins, a irrigué les représentations russes concernant les montagnards du Caucase du Nord. À l'époque soviétique, des abreks organisaient depuis la clandestinité des rébellions contre le pouvoir. Sur la gamme de qualificatifs assignés aux Tchétchènes, au fil des deux guerres, voir Russell J., "Mujahedeen, Mafia, Madmen...: Russian perceptions of Chechens during the Wars in Chechnya, 1994-1996 and 1999-to date”, Journal of Postcommunist Studies and Transition Politics, 18-1, 2002, pp. 73-96 ; Russell J., "Terrorists, Bandits, Spooks and Thieves: Russian demonisation of the Chechens prior to and since 9/11", in Special Issue "The Politics of naming: Rebels, Terrorists, Criminals, Bandits and Subversives”, Third World Quarterly, 26-1, 2005, pp. 101-116. 
En ce qui concerne l'histoire comme enjeu de reconnaissance, le traitement par le pouvoir russe de différentes entités au Caucase fait également l'objet de débats. Des écrivains et historiens tchétchènes (Abouzar Aïdamirov, Mairbek Vatchagaev notamment) remettent en cause la doctrine officielle soviétique du « rattachement volontaire » des Tchétchènes à l'Empire tsariste ${ }^{65}$, insistant sur la résistance et les modalités d'annexion. Le paradoxe est alors souligné entre le prix humain payé par les Tchétchènes sur le temps long pour résister à la conquête, puis pour tenter de se libérer, sans succès, et la facilité avec laquelle la Géorgie accède à l'indépendance en 1991 alors qu'elle avait sollicité un protectorat de l'empire russe en 1793. Les statuts administratifs différenciés nés du processus de construction des entités territoriales à l'époque soviétique 66 alimentent incompréhension et ressentiment dans une partie de la société tchétchène ; au terme de négociations menées dans les années 1920 67, les trois républiques sud-caucasiennes ont en effet obtenu le statut de républiques de l'Union, au contraire de la Tchétchénie et de l'ensemble du Caucase du Nord, intégrés à la Russie comme républiques dites autonomes. C'est pour tenter de dépasser cette hiérarchie de statuts et accéder légalement à l'indépendance qu'une fraction de parlementaires tchétchènes envisagent, en 1990, la partition de la Tchétchéno-Ingouchie pour ensuite demander un statut rehaussé de république de l'Union pour la Tchétchénie et demander à ce titre à sortir de l'URSS, selon les procédures prévues par la loi soviétique 68 .

Événement traumatique de l'histoire tchétchène, la déportation de 194469 est mobilisée dans la quête de reconnaissance. Largement invoquée, notamment par le premier président indépendantiste tchétchène $\mathrm{D}$. Doudaev 70 issu

64. Sur l'utilisation du terme de wahhabites, voir par exemple Cherbatova S., «Tak nazyvaemye vahhabity ", in Furman D. E. (ed.), Chechnya $i$ Rossiya, obshchestvo $i$ gosudarstvo (Tchétchénie et Russie : sociétés et États), Moscou, Publication du Musée Andreï Sakharov, 1999 ; Malashenko A., Trenin D., Vremja Yuga, op. cit.

65. Le professeur Vinogradov de l'Université de Grozny était connu pour développer ces thèses dans les années 1970 et 1980. Entretien avec Moussa Basnoukaev, Grozny, 12 avril 2004.

66. Radvanyi Jean, «Un héritage paradoxal : la fabrication des entités nationales territoriales au Caucase ", in Longuet-Marx F. (ed.), "Le Caucase : axes anciens, nouveaux enjeux », Nouveaux mondes, Eté 1998, Genève, 8, pp. 1-7.

67. Silvia Serrano rappelle ainsi qu'après l'injonction donnée par Lénine en 1921 d'organiser l'intégration économique de tout le Caucase du Sud, il fut question, dans un second temps, de procéder à une intégration politique et territoriale qui devait se faire en deux temps, via l'établissement d'une fédération transcaucasienne devant ensuite être intégrée à la Russie : «Les Républiques doivent d'abord abandonner leurs pouvoirs à une fédération transcaucasienne, puis celle-ci transférerait ses prérogatives à la Russie ", Serrano S., Géorgie, sortie d'empire, Paris, CNRS, 2007, pp. 178-179. En 1922, une commission présidée par Staline prévoit un État fédéral qui engloberait les républiques du Caucase du Sud, dont le statut serait ramené à celui de républiques autonomes au même titre que les républiques du Caucase du Nord. Le refus des Géorgiens et des Ukrainiens fait reculer ce projet, et les républiques sud-caucasiennes obtiennent alors un statut égal à celui de la RSFSR.

68. Akhmed Zakaev, qui fut ministre de la culture du gouvernement tchétchène indépendantiste, rappelle cet argumentaire dans une conférence à la SOAS en novembre 2005 à Londres. Voir aussi Basnukaev M., « Obshchestvenno-politicheskie realii postsovetskoj Chechni » (Les réalités socio-politiques de la Tchétchénie post-soviétique), Central'naya Azia i Kavkaz, 1-19, 
d'une génération marquée par cet événement, la déportation est fréquemment évoquée dans les rassemblements en Tchétchénie durant la perestroïka et pendant les années du régime doudaevien (1991-1994), tandis que des travaux d'historiens émergent sur la base d'archives et de témoignages jusque-là tabous ${ }^{71}$. Dans leurs interventions ou interviews, les deux présidents indépendantistes successifs, D. Doudaev et A. Maskhadov, tout comme leurs représentants, mentionnent régulièrement la déportation comme un des spectres rémanents et l'une des illustrations de la nécessité de se libérer du cadre politique et juridique russe, mettant en jeu une reconnaissance internationale comme clé de la garantie de sécurité pour le peuple tchétchène ${ }^{72}$. C’est en raison des exactions massives contre les civils durant les deux guerres post-soviétiques, et dans le souvenir de la déportation de 1944 et de la décimation de la grande guerre du Caucase, que le terme de génocide est mobilisé tant par des civils que par des porte-parole politiques. Pour la population civile qui subit les bombardements massifs, les massacres du début de la guerre puis les opérations de «nettoyages 73 » de l'armée russe, c'est évidemment bien de guerre qu'il s'agit, et la perception collective d'une extermination à intervalles répétés " tous les cinquante ans 74 » conduit à une "inflation qualificatrice », le recours au registre ultime du génocide apparaissant comme le seul moyen d'attirer l'attention, d'éviter l'oubli et de provoquer une réaction internationale. Elle indique aussi comment l'histoire est mobilisée pour construire un récit national actualisé et alimenté par l'ampleur de la répression contre la population civile et par le discours du pouvoir qui, en confondant combattants et civils dans une désignation stigmatisante, refuse d'appliquer le droit de la guerre aux uns et de garantir la protection aux autres. L'ampleur des violations contre les civils et le non-respect des conventions internationales concernant les combattants, souvent liquidés au nom de la lutte contre le terrorisme, illustre la force performative de la (non) qualification.

2002. Dans le contexte de libéralisation politique sous Gorbatchev, la loi fédérale du 26 avril 1990 édicte les conditions de sortie de l'Union soviétique pour les républiques de l'Union, via l'organisation d'un double référendum.

69. Le 23 février 1944, l'ensemble des Tchétchènes et des Ingouches ont été déportés en Asie centrale. Voir Campana A., Dufaud G., Tournon S., (ed.), Les Déportations en héritage. Les peuples réprimés du Caucase et de Crimée, hier et aujourd'hui, Rennes, PUR, 2010.

70. Voir en particulier Doudaeva A., Le Loup tchétchène. Ma vie avec Djokhar Doudaev, Paris, Maren Sell, 2005. L'adoption d'une résolution par le Parlement européen en 2004 qualifiant la déportation du peuple tchétchène de 1944 de génocide revêt, dans ce contexte, une force émotionnelle considérable, en pleine seconde guerre de Tchétchénie, pour les Tchétchènes restés en Tchétchénie tout comme pour ceux qui se sont exilés.

71. Les recueils publiés par Svetlana Alieva, Tak eto bylo (Ça s'est passé comme ça), en 1993, sont une des premières publications qui diffusent au grand public des témoignages directs sur la déportation. Le journal Doch publie chaque année, à l'occasion de l'anniversaire de la déportation, des interviews, témoignages et analyses sur cet événement (www.doshdu.ru)

72. Voir par exemple l'entretien mené par M. Perevozkina avec A. Maskhadov, «Vive la Tchétchénie libre! », Politique internationale, 75, printemps 1997, pp. 145-154.

73. Opérations de zatchistka: les forces fédérales encerclent des quartiers et procèdent à des rafles, emmenant des hommes dans le système de «filtration », où leurs familles sont contraintes de venir les racheter, morts ou vivants.

74. Intervention d'Oumar Khanbiev, ministre de la Santé du gouvernement Maskhadov, Théâtre de la Cartoucherie, Paris, mars 2002. 
Les parties, désirant mettre un terme à leur antagonisme pluriséculaire et tendant à établir des relations égales mutuellement bénéfiques s'accordent pour rejeter pour toujours l'usage de la force pour résoudre leurs différends et pour développer leurs relations sur les principes et normes généralement reconnus du droit international 75 .

Ainsi sont formulés les articles 2 et 3 du très court « Traité de paix et principes établissant les relations entre la Fédération de Russie et la république de Tchétchénie-Itchkérie » signé le 12 mai 1997 entre le président russe Boris Eltsine et le tout nouvellement élu président indépendantiste tchétchène $A$. Maskhadov, à l'issue de la première guerre puis d'élections libres et plurielles organisées en janvier avec l'implication et la supervision de l'OSCE. Ce texte matérialise un fait unique dans l'histoire des relations russo-tchétchènes : la reconnaissance réciproque de l'adversaire, qui plus est d'égal à égal et basée sur le droit international. En amont de cet accord de paix, le satisfecit délivré par le président du Conseil de la Fédération (chambre haute du Parlement de Russie) Egor Stroev au lendemain de l'élection d'A. Maskhadov est parlant : il salue la « maturité du peuple tchétchène » 76 qui a majoritairement accordé son suffrage à une figure modérée, prête à coopérer avec Moscou et à faire des concessions, et non pas aux vues beaucoup plus radicales de Ch. Bassaev. E. Stroev invite A. Maskhadov au Conseil de la Fédération 77 dès son élection, signe de l'ambivalence qui marque l'attitude des autorités russes quant au statut de la Tchétchénie. Certes, la démarche témoigne d'une reconnaissance de cette figure politique en tant que chef élu d'une province nord-caucasienne. Mais de fait, en l'invitant ainsi à siéger au Conseil (à l'instar de tout chef d'exécutif d'une entité fédérée de Russie, selon les dispositions constitutionnelles en vigueur à l'époque), il refuse de reconnaître l'indépendance tchétchène.

Cette reconnaissance partielle et sélective par les autorités russes est au cœur de notre problématique : d'un côté, A. Maskhadov est légitimé par les autorités russes comme interlocuteur politique, non seulement lors des négociations en 1996, mais également après l'élection de janvier 1997 et encore lors du Traité de paix de mai 1997 - contrairement à D. Doudaev que B. Eltsine avait toujours refusé de rencontrer, y compris pendant les années 1991-1994, et avec qui il avait refusé de négocier ${ }^{78}$; d'un autre côté, cette reconnaissance

75. «Peace Treaty and Principles of Interrelation between the Russian Federation and the Chechen Republic of Ichkeria, 12 May 1997 ». La version anglaise du traité figure à la fin de l'ouvrage de Moshe Gammer, op. cit., p. 224.

76. Rossijskaja Gazeta, 30 janvier 1997.

77. Iaroslav Golovine, «Imeet li Chechenskaja Respublika pravo na nezavisimost' ? " (La République de Tchétchénie a-t-elle droit à l'indépendance ?), http://viktorpopkov.narod.ru/novosti/nezavisimost.htm (consulté le 5 septembre 2012).

78. Les quelques échanges de félicitations réciproques de l’année 1991, lorsque B. Eltsine et D. 
d'A. Maskhadov comme interlocuteur ne signifie en rien que Moscou reconnaisse la légitimité du projet indépendantiste tchétchène et ne met pas fin au malentendu fondamental ${ }^{79}$ : A. Maskhadov est certes un homme politique formé par le système soviétique, prompt à dialoguer avec Moscou et à faire des concessions, mais il est porteur d'une rhétorique indépendantiste qui, même si elle est plus modérée que ses opposants plus radicaux, incarne le projet séparatiste.

La tension qui existe entre reconnaissance de l'adversaire politique et nonreconnaissance de la légitimité de son projet présente là un nœud central. Cette reconnaissance fut éphémère puisque $\mathrm{A}$. Maskhadov se verra taxé de terroriste en 1999 et ainsi rétrogradé au même rang que $\mathrm{Ch}$. Bassaev alors que non seulement il ne revendique aucun acte terroriste mais de plus les condamne. La manière dont le pouvoir russe a géré les actions terroristes menées par des combattants tchétchènes au cours des deux conflits témoigne d'une forte différence d'approche entre B. Eltsine et V. Poutine ${ }^{80}$. La dégradation de l'image de l'adversaire tchétchène est saisissante : durant le premier conflit, non seulement le pouvoir russe négocie avec A. Maskhadov, alors chef des forces armées indépendantistes tchétchènes, mais le Premier ministre russe Viktor Tchernomyrdine négocie directement avec $\mathrm{Ch}$. Bassaev par téléphone en juin 1995, au cours de la prise d'otages de l'hôpital de Boudionnovsk dont ce dernier est l'instigateur. En ce sens, malgré la stigmatisation des combattants tchétchènes comme " bandits " par le discours officiel russe ${ }^{81}$, la négociation en direct avec $\mathrm{Ch}$. Bassaev confère à ce dernier une certaine légitimité. À l'inverse, aucune reconnaissance même limitée n'est acceptée lors du second conflit : pour Moscou, non seulement il est hors de question de négocier avec Ch. Bassaev, mais A. Maskhadov est lui-même disqualifié dès les explosions de septembre 1999. Le renversement par rapport au premier conflit est saillant. Un consensus au moins partiel sur le dissensus politique de fond avait été

Doudaev ont le même intérêt objectif à œuvrer pour une fin rapide du régime soviétique, restent circonscrits dans le temps. Il reste intéressant de noter que jusqu'à l'automne 1994, D. Doudaev tente d'établir un contact avec B. Eltsine. Une lettre qu'il lui adresse en octobre fait référence tant au soutien apporté au président russe pendant le putsch de 1991 qu'au moment du bombardement du Parlement en octobre 1993, avec l'établissement de comparaisons et l'expression de la nécessité de se soutenir mutuellement. Voir « Pis'mo Dzhokhara Prezidentu Rossii B. Eltsinu » (Lettre de Djokhar au président russe B. Eltsine), in Doudaeva A., op. cit., 2002, pp. 149-150.

79. Le malentendu en termes d'énonciation et de description de la situation est total. Tandis que les indépendantistes considèrent comme une victoire la reprise de Grozny d'août 1996 et le retrait des troupes russes qui s'ensuit, arguant également des boycotts aux élections fédérales de 1993, 1995 et 1996, le pouvoir russe argue du fait que tant la Constitution de 1993 que le renvoi de la décision du statut de la Tchétchénie font toujours de cette dernière un sujet de la Fédération russe. Il y a donc un hiatus entre le fait de reconnaître A. Maskhadov et le fait de reconnaître une quelconque indépendance tchétchène.

80. Voir Le Huérou A., Merlin A., Regamey A., Serrano S., Tchétchénie, une affaire intérieure?, op. cit., pp. 130-131.

81. Rappelons que le discours officiel russe définit la première guerre comme une opération de « désarmement des bandes illégalement formées » devant contribuer au "rétablissement de l'ordre constitutionnel ». 
obtenu à la table des négociations de Khassav-Iourt, mais le remaniement narratif au profit d'une lecture en termes de lutte contre le terrorisme génère un dissensus de plus en plus criant au sujet du dissensus de fond. Ainsi les prises d'otages du théâtre du Nord-Ost en 2002 et de Beslan en 2004 se soldent-elles par une prise d'assaut par les forces spéciales russes sans négociation alors que des revendications politiques sont exprimées par les commandos terroristes tant en 2002 qu'en 2004. Les propositions de médiation sont rejetées et tous les appels lancés par A. Maskhadov restent sans réponse. Le refus catégorique de restituer le corps de ce dernier après son élimination en mars 2005 parachève, d'une certaine façon, le déni de reconnaissance. Son corps est ainsi déshumanisé car il est celui d'un «terroriste » et donc, selon la loi russe, ne peut être inhumé dignement.

La mort de Maskhadov souligne aussi, a posteriori, la manière dont le déni de reconnaissance d'un adversaire légitime a été endossé à la hâte par les exécutifs occidentaux. Après avoir pour la plupart refusé de recevoir des émissaires du président élu au début du second conflit afin de ne pas franchir de ligne rouge vis-à-vis de l'État russe, les diplomates constatent la dérive islamiste de la résistance tchétchène après sa disparition et peuvent regretter à peu de frais l'absence d'interlocuteur politique.

\section{Conclusion}

La reconnaissance par la Russie le 26 août 2008 des indépendances de l'Ossétie du Sud et de l'Abkhazie 82 incite au parallèle avec la non-reconnaissance de l'aspiration indépendantiste tchétchène. Survenant au lendemain de la courte guerre avec la Géorgie, cette double reconnaissance est à comprendre comme une préemption mûrie de longue date ${ }^{83}$ par les autorités russes, qui ne fait guère illusion auprès de la population concernée ${ }^{84}$. Elle s'inscrit cependant en rupture avec les principes affirmés jusqu'alors par les diplomates russes dans les crises internationales - soutien de l'intégrité territoriale des États et respect des principes du droit international -, intervient comme une réponse à la reconnaissance du Kosovo par les Occidentaux et permet de reporter sine die les discussions sur une éventuelle entrée de la Géorgie dans

82. L’Abkhazie et l'Ossétie du Sud étaient des entités autonomes au sein de la Géorgie, dans lesquelles se sont déroulés des conflits suite à leurs proclamations de souveraineté. Les années précédant la guerre de 2008 avaient vu une main mise progressive de la Russie sur ces territoires. Voir Serrano S., "Géorgie : le rêve brisé », Politique internationale, 121, automne 2008, pp. 153-172, www.politiqueinternationale.com/revue/article.php (consulté le 27/09/2012).

83. Felgenhauer P., « Eto byla ne spontannaja, a splanirovannaja vojna » (C'était une guerre non pas spontanée, mais planifiée), Novaïa Gazeta, 14 août 2008. Cette analyse à chaud est confirmée quatre ans plus tard par le président V. Poutine : "Putin Confirms the Invasion of Georgia Was Preplanned ", Eurasia Daily Monitor, 9-152, August 9, 2012, http://www.jamestown.org/single/?no_cache=1\&tx_ttnews[tt_news]=39746 (consulté le 28/09/2012)

84. «Avant, nous étions indépendants, maintenant, nous sommes "reconnus" ", constataient, amers, plusieurs intellectuels abkhazes au lendemain de cette reconnaissance. Entretien avec Salvatore di Rosa, de retour d'Abkhazie, Maikop, juin 2009. 
l'OTAN. Si l'effacement des revendications indépendantistes tchétchènes, qui auraient rendu trop flagrante la politique du « deux poids, deux mesures » 85 , ont facilité la tâche aux autorités russes, ces dernières ont cependant eu besoin de recourir elles aussi à une forme de surenchère dans la labellisation en justifiant l'intervention des forces russes par la nécessité d'arrêter un « génocide » en cours contre le peuple ossète par les forces géorgiennes.

\section{La justice, seul lieu de reconnaissance (partielle) possible?}

D'autres instruments peuvent-ils permettre une forme de reconnaissance, même indirecte ? La perspective pour les Tchétchènes d'être reconnus comme peuple colonial par l'ONU en vertu de la résolution 1514 de décembre 1960 sur l'octroi de l'indépendance aux pays et peuples coloniaux aurait pu être une voie pour porter le conflit à un niveau politique. Le droit de veto de la Russie au Conseil de sécurité rend irréaliste une telle approche, qui par ailleurs risquerait d'ouvrir une boîte de Pandore sur l'apparition de «peuples coloniaux» dans des États issus d'empires d'un seul tenant géographique.

Largement insatisfaisante et très partiellement réparatrice, la justice est sans doute le terrain sur lequel peut s'exercer ce que l'on pourrait définir comme un ersatz de reconnaissance. À défaut de reconnaître le conflit pour ce qu'il est, de nombreux crimes commis pendant son déroulement ont été largement documentés et, grâce à la mobilisation d'ONG et d'avocats, ils ont fait l'objet d'enquêtes et de décisions de justice. Encore faut-il préciser que c'est hors des frontières de la Russie, dans l'enceinte de la CEDH à Strasbourg, que se joue pour l'essentiel la prise en compte de la question tchétchène en l'absence d'un Tribunal $a d$ hoc $^{86}$ et d'une adhésion de la Russie à la Cour pénale internationale.

Les très nombreux arrêts de la $\mathrm{CEDH}{ }^{87}$, s'ils déclarent, dans la plupart des cas, l'État russe responsable de crimes et de violations par le biais de ses agents, ne parviennent cependant pas à faire condamner les responsables ni à transformer la manière dont la justice russe considère ces crimes ${ }^{88}$. Les répa-

85. Merlin A., Serrano S., «États et conflits au Caucase. Préface », op. cit.

86. L'Assemblée parlementaire du Conseil de l'Europe avait demandé la création d'un tel tribunal en 2006 (Rapport de la Commission des questions juridiques et des droits de l'homme. Rapporteur Binding $\mathrm{R}$. (http://assembly.coe.int/Documents/WorkingDocs/Doc05/FDOC10774.htm, consulté le 22/03/2012) et un très gros rapport en vue de sa création a été publié en 2009 par plusieurs experts russes et tchétchènes : Dmitrievski S., Gvareli B., Chelysheva O., Mezhdunarodny tribunal dlia Chechni (Un tribunal international pour la Tchétchénie), t. 1 \& 2, NijniNovgorod, 2009, (texte disponible en ligne sur http://www.tribunalchr.info/, consulté le 22/03/2011).

87. Plus de 200 arrêts ont été rendus à ce jour, condamnant la Russie pour violations et crimes commis en Tchétchénie par l'État russe. http://www.londonmet.ac.uk/researchunits/hrsj/affiliated_centres/ehrac/infringement-proceedings.cfm. (consulté le 30 septembre 2012)

88. Koroteev K., "Legal Remedies for Human Rights Violations in the Armed Conflict in 
rations symboliques et matérielles apportées par les décisions de justice ${ }^{89}$ restent le fruit de décisions extérieures au pays dans lequel se sont déroulés les événements concernés. Les menaces dont sont l'objet les requérants, l'extériorité et la technicité des recours devant la CEDH sont autant d'éléments qui limitent la possibilité de parvenir à la constitution des victimes en sujets de droit et acteurs de la réparation judiciaire, la Russie fournissant de ce point de vue un contre-exemple certain à « l'omniprésence des victimes » mise en avant pour d'autres situations post-conflits ou de sortie de dictature 90 .

Convaincus que la reconnaissance par la justice nationale des responsabilités dans les crimes commis est une étape-clé d'une possible réconciliation, d'un dépassement des violences de la guerre, d'autres acteurs - non gouvernementaux pour la plupart - s'engagent, après l'avocat Stanislav Markelov ${ }^{91}$, assassiné en janvier 2009, dans des procédures exemplaires mais qui n'aboutissent que rarement auprès des tribunaux russes.

Ces initiatives sont en effet de peu de poids face à l'absence de volonté politique pour engager une démarche de justice transitionnelle supposant un travail de reconnaissance, de réconciliation et de pacification en profondeur ${ }^{92}$, et à l'oubli progressif de la guerre elle-même au profit d'une présentation de la Tchétchénie et du Nord-Caucase comme des régions en proie à une violence endémique que la Russie financerait trop généreusement. La société russe, notamment dans son rapport aux Nord-Caucasiens (qui sont pourtant citoyens de Russie, rappelons-le), de même que la société tchétchène continuent d'être traversées par des logiques de violence et de ressentiment et portent la trace des crimes commis et non réparés. Les agissements du régime tchétchène loyal à Moscou dirigé par Ramzan Kadyrov, malgré la reconstruction matérielle, en sont un signe, de même que la montée des tensions nationalistes en Russie, particulièrement à l'encontre des Nord-Caucasiens.

Chechnya: The Approach of the European Court of Human Rights in Context", Journal of International Humanitarian Legal Studies, 1-2, 2010, pp. 275-303.

89. Natalia Estemirova, membre de l'ONG de défense des droits de l'homme Mémorial en Tchétchénie, assassinée en juillet 2009, soulignait l'ambivalence que revêtaient pour les familles de victimes les arrêts de la $\mathrm{CEDH}$, d'autant que la partie russe, si elle paie les compensations, n'initie ni les réformes recommandées par les arrêts, ni ne poursuit les agents comptables des crimes sur son territoire. Entretien de Natalia Estemirova avec Mylène Sauloy, Grozny, avril 2009.

90. Lefranc S., Mathieu L. (eds.), Mobilisations des victimes, Rennes, Presses universitaires de Rennes, 2009.

91. Merlin A., «Le pouvoir de la loi contre la loi du pouvoir - Entretien avec Stanislav Markelov, avocat, Moscou, 3 juin 2008 ", The Journal of Power Institutions in Post-Soviet Societies [Online], 9, 2009, URL : http://pipss.revues.org/2243, consulté le 30 septembre 2012. C’est aujourd'hui le sens des activités du Joint Mobile Group créé en Tchétchénie en 2009 à l'initiative de l'ONG "Comité contre la torture ", pour mener le plus loin possible les procédures judiciaires internes.

92. Nadeau C., Saada J., Guerre juste, guerre injuste..., op. cit.; Walzer M., Guerres justes et injustes. Argumentation morale avec exemples historiques, Paris, Folio Gallimard, 2006. 